\title{
An epic note
}

Epic was mercifully short, 120 characters devoid of emotion, to let me know that my patient suddenly died on Sunday morning after Father's Day.

The email was waiting on Monday morning, ensuring that I would open the secure twenty word note

not on the day of dying,

but alone in my office,

taking away my choice to answer a page, to pick up a phone,

to have a face to face conversation

with the colleague who fielded the call,

or to attend the funeral

that had occurred the previous day,

to witness ancient and sacred healing rituals,

or even to write the cause on the death certificate.

I wasn't there to wrap my arms around a grieving spouse who certainly felt as scared as an abandoned baby bird that does not understand why death came that day or why time suddenly stopped.

Everything unraveled that previously seemed secure only months, weeks, even seconds before a heart stopped, like a jigsaw puzzle that was previously framed, then crumbled into many jagged pieces.

Later that evening, I dropped by to sit with the family, believing that I was finally doing my job.

Who knew that the father was such a pillar holding together not just one family, but a community of immigrants coming and going, welcoming and sending off?

Who knew that love of family could overcome my inability to answer why this great man died so swiftly?

Did he suffer?

Were there warning signs?

Did he say anything to each child, to his wife, before he died?

Each testimony mixed tears with smiles, sadness with laughter as they recounted old jokes told many times, ending with words that promised healing: "Your father taught you all to stay together."

We offered each other hugs, and I felt more secure knowing that my job was also to help myself heal, for none of us are alone in sorrow, no matter where we are when death comes. 
Adam 0 Goldstein

Correspondence to Adam 0 Goldstein, University of North Carolina, Department of Family Medicine, North Carolina, USA; adam_goldstein@med.unc.edu

Competing interests None.

Provenance and peer review Not commissioned; internally peer reviewed.

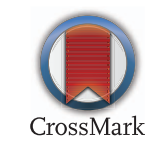

To cite Goldstein AO. Med Humanit 2015;41:e3.

Med Humanit 2015;41:e3. doi:10.1136/medhum-2014-010604 